\begin{tabular}{l|l|l}
$\begin{array}{l}\text { Università } \\
\text { della } \\
\text { Svizzera } \\
\text { italiana }\end{array}$ & $\begin{array}{l}\text { Faculty } \\
\text { of Economics }\end{array}$ & IdEP Economic Papers \\
& & \\
\hline & & $2014 / 09$
\end{tabular}

F. Mazzonna, P. Salari

Short term effects of public smoking bans on health 


\title{
Short term effects of public smoking bans on health*
}

\author{
Fabrizio Mazzonna \\ Università della Svizzera Italiana (USI) and $\mathrm{MEA}^{\dagger}$ \\ Paola Salari \\ Università della Svizzera Italiana (USI)
}

September 15, 2014

\begin{abstract}
This paper evaluates the causal negative effect of environmental tobacco exposure on health by exploiting the time and geographical variation in public-place smoking bans implemented in Switzerland between 2007 and 2011. Using monthly data from the universe of Swiss hospitals between 2004 and 2012, we show that the incidence of acute myocardial infarction hospitalizations decreases by about 10-12\% immediately after the law implementation. We also find evidence of heterogeneity by age and sex and across income and education groups. In particular, the policy affected mainly men aged $50+$ and the regions characterized by a lower level of income and education.
\end{abstract}

\section{Keywords: .}

JEL codes: C23, H75, H77, I14, I18.

\footnotetext{
*Corresponding author: Fabrizio Mazzonna, Università della Svizzera Italiana, via G. Buffi 13, 6904 Lugano, Switzerland (fabrizio.mazzonna@usi.ch). We thank Giovanni Pedrazzini, Raphael Parchet, Patrick Gagliardini, Andrea Ichino, Osea Giuntella and seminar participants at Università della Svizzera Italiana for useful comments. We are grateful to the Swiss Federal Office of Statistics (Health and Social Affairs Division) for providing us the data.

${ }^{\dagger}$ Munich Center for the Economics of Ageing at Max Planck Institute for Social law and Social Policy.
} 


\section{Introduction}

The negative effects of smoking - both primary and second hand - are well known and subject of many studies. In a recent review study, Cawley and Ruhm (2011) show that smoking is the most important modifiable risk factor related to both mortality and disability and the most damaging health behavior in high-income countries. A recent report by the American Hearth Association (2014) estimates a total cost associated with smoking of $\$ 193$ billion per year, $50 \%$ due to direct medical costs and $50 \%$ due to productivity costs. Smoke also contributes to health inequality since smoking prevalence and environmental tobacco smoke (ETS) exposure are higher among people from low socio-economic status (SES) (e.g. Cutler and Lleras-Muney 2010). The public awareness about the large negative effects of smoking induced several governments all over the world to enact a series of measures to reduce tobacco consumption and ETS exposure. Among them, smoking ban in public places is one of the most important public health intervention implemented in many developed countries in the last decades. However, several concerns have been raised-in particular among economists (e.g. Adda and Cornaglia 2010)_about the real health benefits deriving from this public health intervention.

This paper investigates the short term effect of public smoking bans on the incidence of acute myocardial infarction (AMI), which represents the main cause of death in almost all OECD countries (OECD 2013). In particular, exploiting the time and geographical variation in the introduction of smoking ban in public places in Switzerland, we show that the incidence of AMI decreases on average by about $10-12 \%$ immediately after the law implementation with large heterogeneity across population sub-groups. Moreover, using this quasi-natural experiment, we provide evidence of a causal association between ETS and AMI.

Previous economic studies mainly analyze the effect of smoking ban on smoking behavior, while they are limited in the ability of studying the effects of smoking bans on objective health outcomes. This might be explained by the fact that the negative effects of smoking on most of the associated diseases may generally require long times of observations.

For instance, the effect of smoking on lung cancer may be detected only in the long run. A change in smoking behavior - such as the individual decision to quit smoking - is, by contrast, easier to measure. Therefore, it represents an outcome to assess the effect of the anti-smoking policy in the short run. However, the evidence from these studies is quite mixed. In the US, Evans et al. (1999) show that smoking ban on workplaces reduced smoking prevalence by $5 \%$. On the other hand, Adda and Cornaglia (2010) report evidence of displacement of ETS from public (bars and restaurants) to private places and no effect on smoking prevalence. In Canada, Carpenter et al. 
(2011) find that these policies had no effect on smoking prevalence, but induced large reduction in public-places ETS exposure without any private displacement. The introduction of smoking bans in public places had limited or no effects on smoking prevalence also in Germany (Anger et al. 2011) and UK (Jones et al. 2013), while there is evidence of a reduction in smoking prevalence and consumption in Italy (Buonanno and Ranzani 2013). Given the well-know negative association between smoking and body weight (e.g. Cowley et al. 2004), some studies evaluate the effect of this policy also on other health behaviors, showing some evidence of weight gains and increasing alcohol consumption after the introduction of the smoking ban in Italy and in the US (Liu et al. 2009 and Pieroni et al. 2013). All in all, the risk of negative spillovers on other behaviors, together with the evidence of displacement from public to private places, might explain the previously mentioned concerns about the health benefits of this policy.

We contribute to the literature by focusing on AMI hospitalizations, which allow us to objectively measure the short-run effects of smoking bans on an objective metric of health. A wide strand of the literature argues that smoking is the most important avoidable cause of coronary diseases (Glantz et al. 1991). In particular, several studies show that it is associated with a greater risk of AMI, especially among men (Teo et al. 2006). From a medical point of view, exposure to smoke is associated with an endothelium-dependent dilatation, which may lead to an early arterial damage, as well as with a tendency towards an acute enhanced platelet aggregation (Celermajer et al. 1996; Sargent et al. 2004). Both factors occur within 30 minutes after exposure to smoke and are both risk factors for AMI. A reduction in the number of AMIs is thus quantifiable immediately after the introduction of the smoking ban, being it evident starting from the initial days after the reduction of smoking exposure (Richiardi et al. 2009; Argacha et al., 2008). This means that we can evaluate the short-term effect of this policy.

We are fully aware of the previous epidemiological literature investigating the effect of smoking bans on cardiovascular diseases. For instance, in a meta-analysis of the existing literature, Meyers et al. (2009) argue that after smoking ban's implementation, AMI risk decreases by $17 \%$ overall, with a bigger effect among younger individuals and non-smokers. However, there are fundamental concerns regarding the identification assumptions behind the estimation strategies implemented in these studies. Most of them are based on a simple pre and post comparison in a single city or country (e.g. Di Valentino et al. 2011 on the Swiss canton Ticino) without accounting for all potential confounders, such as preexisting trends or the effect of contemporaneous policies. To this end, Shetty et al. (2011) find that the relationship between smoking bans and AMI in the US is sensitive to the choice of the city and specification. For instance, using data about US-Medicare enrollees aged 66+ for the years 1999-2008, Barr et al. (2012) show that the negative effect of 
smoking bans on AMI hospital admissions disappears as they account for non-linear adjustment for secular trend and random effects at the county level. Finally, some of these studies evaluate the effect of smoking bans in very small cities and this may lead to problems of external validity of their results (e.g. Sargent et al. 2004).

In our estimation strategy we address all these concerns. In particular, we exploit the Swiss quasi-natural experiment to assess empirically whether there is a causal effect of the smoking ban on AMIs. Switzerland is a perfect environment to study, since the 26 Swiss cantons implemented the public smoking ban at different points in time, making it possible to exploit both time and geographical variation. We use monthly data on the universe of Swiss hospitals admissions observed from 2004 to 2012, broken down by age and sex. This allows us to evaluate the heterogeneity of our results. In particular, the reduction in AMI hospitalization has been larger in absolute terms for men aged 50-65 and 66+, while we find some effects only on women $66+$, the only subgroup among women at risk of AMI. It is worth noting that in relative terms (compared with the mean incidence of the disease in the population) the larger effect is found among men under 66 (both under 50 and 50-65). These subgroups should attend bars and restaurant more often than the older subgroup (men 66+), and so they were more affected by the public smoking ban.

Moreover, exploiting the residential information on the hospitalized patients, we can conduct our analysis both at cantonal and regional level. For the regional level we use of the so-called Spatial Mobility regions, 106 smaller geographical units that allows us to evaluate the heterogeneity of our results across areas with different level of income and education, holding constant the confounding effect of different institutional settings at cantonal level. In particular, we find that the effect of the policy on AMIs has been stronger in low income and low educated areas. This might be due to the fact that in low SES areas there is a larger incidence of smokers who are affected by the smoking restrictions in public places.

We evaluate the robustness of our results to alternative model specifications. In our estimation strategy we account for many factors that might confound our results, such as area (canton or region) and time fixed effects, as well as area specific time trends. We also control for local unemployment rate to take into account the well-know pro-cyclical behavior of smoking and AMIs (Rhum 2005 and 2007) and to take into account the effect of the last financial and economic crisis.

We indirectly test our main identification assumption by checking whether the policy also affected the incidence of lung, prostate and breast cancer which are known not to have been affected by the policy, at least in the short run. We also show that the reduction was larger during the winter period, when people are more likely to seat inside public places. Moreover, we implement a "placebo" test (by using one year lag and lead values for the treatment) to assess concerns about 
the potential endogeneity of the policy (Carpenter et al. 2011) and to rule out the possibility of other confounders or external shocks driving our results.

Our results are particularly relevant from a health policy perspective. First they shed a light on the doubts raised by previous literature on the effectiveness of this policy. We report evidence of large positive benefits on health already in the short-term, by showing a reduction in AMI incidence, the most important cause of death related to ETS together with lung cancer. Second, our results suggest potential benefits also on health inequality, since we show that the ban had stronger effects in areas characterized by lower SES (low income and education).

The next section describes how and when the smoking bans were implemented in the Swiss cantons. Section 3 presents the dataset and some descriptive evidence. Section 4 explains the choice of the model and discusses some empirical issues. Section 5 shows and compares our main results and introduces some robustness checks. Finally, section 6 concludes.

\section{Swiss institutional setting}

Smoking bans in Switzerland were implemented only after a long series of anti-smoking initiatives undertaken some years before and mostly defined at federal level. In 2001 the Swiss Federal Council adopted the National Tobacco Control Program, aimed at sensitizing people towards the bad effects of smoke and at changing smoking behavior. The Program devoted economic resources for antismoking campaigns and other measures and was meant to last until 2005, but it was extended until 2008 and subsequently until 2016 (under the new name of National Tobacco Program). To guarantee the necessary economic resources for anti-tobacco initiatives, in 2004 the Federation set up also the Tobacco Control Fund, financing it through a tax of 2.6 centimes on each cigarette packet sold. It supported measures aimed to assist people who wanted to give up smoking and to protect non-smokers against second-hand smoke. It was in this setting that in April 2007 canton Ticino decided to implement a smoking ban in all public places (i.e. bars, restaurants and clubs), with the aim of contrasting smoke and protecting the population against second-hand smoke. Ticino was the first canton opting for such a policy. Canton Grisons followed Ticino one year later.

In May 2010 a federal law regarding the implementation of the smoking ban came into force (it was enacted already in October 2008): smoking in bars and restaurants was prohibited in each canton. The federal law was less restrictive than the one approved in canton Ticino. It allowed restaurants to have some rooms for smokers, and even the service may be guaranteed in some cases. However, cantons were free to set the federal law only as a lower bound and to choose more restrictive regulations. Anticipating the implementation of the federal law, all the other cantons adapted and introduced the public smoking ban during 2009 and 2010. The last canton to introduce 
the ban was Appenzell O.Rh. at the beginning of 2011.

Table 1 shows for each canton (first column) when the smoking ban in public places started to be in force (second column) and the strictness of the law that they chose to adopt (third column). The majority of cantons decided for a more severe regulation, meaning that they chose not to dedicate special rooms for smokers. It is worth remarking that there seems to be a sort of "linguistic" trend in the timing of smoking bans implementation: the Italian speaking cantons were the first cantons to implement this policy, followed by most of the French speaking cantons and lately, by the German speaking cantons. It is likely that the choice of a canton whether to implement the smoking ban was also affected by the choice of neighbor territories, both Swiss and non-Swiss.

\section{Data}

We use data from the "Swiss Hospital Statistics" (HOST), provided by the Swiss Federal Statistical Office. It is a wide dataset collecting information on each patient for the universe of the Swiss hospitals from 1999 to 2013; after 1998, it became compulsory for each hospital to participate at this statistics. HOST includes basic demographic information (age, sex and residence) for each patient, and information on the main diagnosis, as well as secondary diagnoses. For our analysis we use data from 2004 to 2012, due to the lack of some hospitals data for the years before 2004. Since the dataset is based on individual data, we are able to explore the heterogeneity across different classes of population by carrying out separated estimates for different groups of patients (according to age and sex). Concerning patients geographical residence, Switzerland was split in more than 700 geographical regions called "Medstat regions": each of them counting from 3.500 to 10.000 inhabitants and including territories similar from a socio-economic and geographical point of view. In 2008 the Swiss Federal Statistical Office implemented a major redefinition of the Medstat regions, changing substantially the agglomeration of municipalities that form each region. The rationale behind this redefinition was to have more homogeneous and comparable areas across the country. Unfortunately, for the aim of our research, this change does not allow us to analyze the impact of the smoking ban policy at this geographical level because the same areas are not comparable before and after the redefinition. For this reason, we consider two other geographical levels for our analysis: the 26 cantons and the so-called Spatial Mobility (SM) regions, 106 geographical units that are smaller than cantons but larger than the Medstat regions. ${ }^{1}$

\footnotetext{
${ }^{1}$ Knowing the zip codes grouped in each Medstat and in each SM region, we are able to group the Medstat regions into the larger SM regions. Nevertheless, in some cases the Medstat regions cannot be uniquely assigned to one SM region. In these cases we split the number of AMIs of the Medstat region and we assign it to the SM regions to which the Medstat region belongs. We use as a weight the number of zip codes of the Medstat that belong also to the SM region divided by the total number of zip codes that compose that Medstat.
} 
Carrying out the analysis at cantonal level is an advantage because cantons coincide with the political area of the introduction of the smoking bans. On the other hand, focusing on the SM regions (hereafter regions) allows us to exploit the heterogeneity of the effect across income and education levels (see also Section 4). To be able to exploit these potential sources of heterogeneity, we added to our dataset some socio-demographic information: population, income, education and unemployment rate. Data on population for cantons and municipalities is provided by the Swiss Federal Statistical Office. We aggregate data of municipalities to obtain data at regional level. However, the population breakdown by sex and age is available only for cantons, while for municipalities this information is provided only in the 2000 census. To obtain a proxy of the regional population by age and sex for the years 2004-2012, we multiply the value of the regional population of the year 2000 (from the municipal census) for the rate of variation of the population of the canton to which the region belongs. We do this for each age and sex category.

Monthly data is available only for unemployment rates, while for income and education we have data only for few years. We extract data on unemployed from the website of the State Secretariat for Economic Affairs (sector of job market statistics) for the years 2004-2012. Data is taken from the official registers of unemployed. It is monthly updated and available both at cantonal and regional level.

Data on education is available in the Statistical Atlas of Switzerland for the year 2000. For each region we compute the share of people with only compulsory primary education, the share of people with a degree of second level (high school) and the share of people with a degree of third level (college). Finally, we use data on income from the Swiss Federal Tax Administration website for the year $2000-2010 .^{2}$

\subsection{Descriptive statistics and graphical evidence}

Table 2 shows in the first two columns the monthly average and standard deviation of AMI hospital admissions for the whole population by area and and by sex in the years 2004-2012. In the third column we report the corresponding incidence per 100'000 inhabitants by dividing the number of AMI cases in each canton for the corresponding population. Similarly, the last column reports the incidence based on regions. Consistent with the medical literature, two thirds of the AMI hospital admissions are among men, in particular among those in the age class 50-65 and 66+, while for women the incidence of AMIs is almost only among women aged $66+$. There is evidence of substantial variability in the number of AMI hospital admissions not only across cantons but

\footnotetext{
${ }^{2}$ We cannot insert the income in our estimation as a time varying variable because up to now the last available year is 2010. For this reason we use a mean of the median income in each region in the period 2004-2010.
} 
also over time. We observe an increasing trend in AMI hospital admissions over the years under investigation: this may depend on better measures of prevention, on better access to health care and on changes in the definition of the diagnosis, especially after a recent reclassification of some angina patients into AMI cases (Insam et al., 2013). We crosschecked our dataset with data from the AMIs Plus - the National Registry of AMI in Switzerland - and we confirmed the consistency of HOST data and the presence of the increasing trend. There is also evidence of seasonality with a larger incidence of AMI during the holiday season. This descriptive inspection suggests that taking such spatial and time heterogeneity into account in our estimation strategy is crucial. HOST collects about $90 \%$ of the total estimated number of AMI cases: the remaining $10 \%$ are people who die from AMI before arriving to the hospital (Meyer et al., 2007 perform this estimation for the year 2004). This small percentage is expected to further decrease over time, due to the easier access to hospitals in many areas. Cantonal and regional values present some small differences, due to the statistical approximation of our computations. Cantonal values tend to underestimate the big areas. Notice that the mean incidence of AMI hospitalizations is slightly larger at regional level than at cantonal level. This difference arises because the cantonal mean gives the same value to all cantons, regardless of the population's size. By contrast, the mean incidence at regional level is closer to the true national value.

In Figures 1 and 2, we show first evidence of a discontinuity in the number of AMI hospital admissions at national level in correspondence of the smoking ban implementation for men but not for women. Since each canton implemented the policy at different points in time, we aggregate AMI cases across different cantons based on the distance in months from the policy implementation, as in a sort of Regression Discontinuity Design (RDD). More specifically, in Figure 1 we show the raw data, while in Figure 2 we report the aggregate residuals from a regression in which we control for year and canton fixed effects. This second figure is meant to take into account the time and geographical heterogeneity described before. The vertical line represents the "month zero, namely the month during which each canton introduced the ban. Purely for descriptive purposes, the fitted lines are based on a quadratic fit on the two years before and after the implementation of the policy, while the shaded areas correspond to the $95 \%$ confidence interval.

For men, Figure 1 already shows evidence of a discontinuity in AMI cases after the introduction of the smoking ban, although we are not controlling for temporal trends and cantonal differences. This discontinuity is confirmed in Figure 2, where we take into account these potential confounding factors. In particular, the residuals are slightly above zero in the two years before the discontinuity, while they rapidly decrease towards -40 in the months immediately after the smoking ban implementation. For women, instead, we do not have evidence of any discontinuity at the cut-off 
date.

Unfortunately, we are not able to show similar evidence for cantons since the number of AMI cases each month is too small to show graphical evidence of a significant discontinuity. In the next section, we investigate the effect of smoking bans on AMI hospitalizations trying to take into account all the potential factors that might confound the effect of the policy. It is worth reminding that, since Figure 2 nets out canton and time fixed effects, we are already controlling for the most important confounding factors in the relationship under investigation.

\section{Empirical strategy}

The empirical strategy exploits the geographical and time variation in the implementation of the smoking ban. In the analysis that follows, the outcome of interest is represented by the AMI incidence rate, $A M I_{k t}$ (as reported in column 3 of Table 2), that is obtained dividing the absolute number of patients hospitalized for AMI in area $k$ (it can be either canton or region) and at time $t$ by the corresponding population of the area $k$ at time $t$. We prefer this variable to the absolute number of AMI cases because it allows us to control for the different dimension (and population structure) of our Swiss regions. Moreover, it nets outs the effect of differential population trends across regions. ${ }^{3}$ More specifically, we estimate the following equation:

$$
A M I_{k t}=\beta_{0 k}+\beta_{1} S B_{k t}+\beta_{2} X_{k t}+\delta_{t}+f(k, t)+\epsilon_{k t}
$$

where $S B_{k t}$ is a dummy equal to one if the smoking ban was enacted in area $k$ at time $t$; the coefficient $\beta_{1}$ measures the effect of the policy. Our specification also includes area, $\beta_{0 k}$, and time, $\delta_{t}$, fixed effects and, as additional robustness check, area specific time trends, $f(k, t)$. More specifically, we model the function $f(k, t)$ as a linear function (i.e. multiplying the geographical dummies for a linear time trend). Finally, $X_{k t}$ includes monthly data on unemployment rate. Ruhm (2005 and 2007) show that both smoking and AMI discharges are pro-cyclical, so we might expect a negative correlation between unemployment and AMIs.

Time is measured in months (108 months starting from January 2004 to December 2012). As already mentioned in Section 3, the geographical unit under investigation, the area $k$, can be either the canton or the region. Since the policy is implemented at cantonal level it is natural to consider the canton as the reference geographical unit. However, we believe that it is still worth to focus the analysis on a smaller geographical area for two main reasons. First, it allows to analyze the heterogeneity in the effect of interest across educational and income levels, holding constant the

\footnotetext{
${ }^{3}$ The other advantage of using the incidence rate is that we can rely on linear regression models and avoid the issue of estimating count data models.
} 
confounding effect of institutional differences at cantonal level. In other words, the analysis at the level of regions exploits the geographical variation within cantons in the level of education and income. Second, the increase in the number of observations allows us to increase the power of our estimation strategy and to reduce the relative weight of smaller cantons. As discussed in Section 3.1, the analysis at cantonal level put the same weights to cantons of different dimensions. ${ }^{4}$

Given the panel nature of the dataset, the baseline estimation method for this model is the within estimator (fixed effects), which allows to remove all time-invariant confounders at area level. Our estimates are separated by sex and age group (below age 50, age 50-65 and age 66+) to take into account the large differences in the incidence of AMIs across these population subgroups. We also implement separated estimates according to the severity of the policy implemented by the different cantons (severe vs. mild policy, see Section 2 for further details).

\subsection{Identification issues}

As discussed throughout the paper, the identification of the effect of the smoking ban on AMIs comes from the time and geographical variation in the implementation of the policy across cantons. Notice that different from a standard "diff-in-diff" strategy, we do not need the classic common trend assumption, since the policy has been implemented in all cantons but at different points in time. Therefore, it becomes crucial that there are no other policy changes or cantonal shocks coinciding with the introduction of the smoking ban and affecting the number of AMIs. The specification proposed in equation (1) should be sufficiently flexible to account for the potential confounding factors at geographical level since it also includes area specific time trends. Our specification also includes local unemployment rates to address the concern that the policy implementation is somewhat contemporaneous with the last financial and economic crisis. However, this is unlikely since the policy implementation has a very large temporal variation that does not coincide with the timing of the crisis (2008-2009).

More generally, we believe that it is very unlikely to have any confounding factors correlated with the policy implementation in each canton and able to affect the number of AMIs at the same time. Unfortunately, we cannot test it directly, but we implement a battery of robustness checks that supports our identification assumption. First, we implement a sort of "unconfoundedness test" in which we test whether the policy has an effect also on the incidence of lung, prostate and breast cancer, that should not be affected by the policy, at least in the short run. Second, as in Carpenter et al. (2011), we implement a placebo test in which we assess concerns about

\footnotetext{
${ }^{4}$ As robustness check we implemented our estimates using weights based on population size. The results we found are slightly larger than those reported in the main text and so very close to the effect estimated using the regions.
} 
the potential endogeneity of the policy by controlling for one year-lead of the smoking ban. Such a test is implemented to verify whether we are confounding the effect of the smoking ban law with other unobservable trends that vary across cantons and in particular whether "large shocks to outcomes systematically precede rather than follow" smoking ban laws. ${ }^{5}$ More generally, we test for the presence of jumps in the AMI hospitalizations distribution one year lag and lead the real implementation of the policy in each canton. Another robustness check we implement is to check whether the effect of public smoking ban is larger during the winter season. The intuition is that during these months people that go to pubs and restaurants are more often inside public places because of the adverse weather conditions, while during the other seasons people should stay more often outside drinking and eating. So if we are not confounding the effect of the ban with that of other confounding factors we should observe a larger reduction in AMIs during the winter season.

Even tough all these tests support our identification strategy, some concerns may still arise regarding the estimation of the standard errors, since in panel data errors are often correlated both across time and regions. In this case it might not be sufficient to cluster standard errors only at the statistical area level (as suggested by Bertrand et al. 2004). It is indeed very likely that the number of AMI cases is correlated also spatially across cantons. The decision of one canton to introduce a smoking ban may have an influence also on the choice of a neighbor canton. In our case, it is quite evident that the timing in the implementation of the policy is somewhat affected by some geo-cultural factors. In particular, Ticino was the first canton to implement the policy in 2007 (probably affected by the Italian smoking ban implemented since 2003), followed by Grisons (always at the border with Italy and with a quite large Italian community). Then, the policy has been implemented since mid 2009 in most of the French cantons, while most of the German cantons implemented the policy only starting from late 2010. This geo-cultural factor in the timing of the policy implementation should not affect the estimated effect of the smoking bans since we control for both canton fixed and canton specific trends. However, such spatial correlation might affect the standard errors of our estimates. To account for this second potential source of correlation we use a two-way clustering strategy implemented by Cameron et al. (2011). As robustness check, we also use the OLS fixed effects estimator with panel-corrected standard errors (PCSE) based on the work of Beck and Katz (1995). It estimates the parameters by OLS and estimates the standard errors and the variance-covariance matrix assuming that the disturbances are by default heteroskedastic and contemporaneously correlated across panels. We also assumed that errors are first-order auto correlated and that the coefficient of the $\mathrm{AR}(1)$ process is specific to each panel.

\footnotetext{
${ }^{5}$ Carpenter et al. (2011) page 49.
} 


\section{Results}

In this section we report the results from our estimation of the effect of the smoking ban on the incidence of AMI hospitalizations using the identification strategy presented in Section 4. Moreover, in Section 5.1 we present the results of a number of robustness checks already discussed in Section 4.1.

We start showing in Table 3 the estimates of the effect of the public smoking ban on the incidence of AMI hospitalizations on total population and by sex. Each column represents a different specification. Specifically, Model A includes area and time fixed effects; Model B adds monthly data on area specific unemployment rates; as a further robustness check, Model C includes area specific linear time trends. Estimates are implemented at cantonal (first set of rows) and regional level (second set of rows). Consistent with the graphical evidence in Figures 1 and 2 (that aggregate data at national level), the table shows robust evidence of a reduction in the incidence of AMI mainly for men. For women, instead, we have evidence of a small and slightly significant effect only in the regional estimates. This result should not be surprising given the very low incidence of AMI among the total women population (see Table 2).

The estimated reduction in the incidence of AMI is robust across all specifications. The estimated effect only slightly decreases in size (but not significantly) when we include area specific time trends. This reduction should be due to the effect of imposing the same linear trend before and after the reform in each area (for this reason from now on we will use Model B as reference). Most importantly, estimates are larger in size - although not significantly - at the regional level. In the total population, it corresponds to a monthly reduction of roughly one AMI case every 100'000 inhabitants (so a reduction of about 1'000 cases per year in Switzerland). Looking at the mean incidence reported in Table 2, the estimated coefficients correspond to roughly 8-9\% reduction in the incidence of AMI according to the cantonal estimates and 10-12\% reduction for the regions. This difference is not surprising since, as aforementioned, cantonal and regional estimates weight the cantons differently. In particular, the cantonal estimates give the same weight to small and big cantons, while in the regional estimates bigger cantons get more weight since they are split in more regions. If the effect is homogeneous across the population the two estimates should converge. However, since most of the smaller regions implemented only a mild regulation against smoking in public places (see Table 1), we might expect a smaller effect on these cantons. This is confirmed by the results provided in Table 6 , where we show larger effects in cantons that implemented the more severe regulation, and by a further robustness check in which we use population weights for 
the canton estimates. ${ }^{6}$ For this reason, in the analysis that follows we only show results for the regions (estimates at cantonal level are always very similar).

Having assessed the impact of the public smoking ban on the total population, we investigate the heterogeneity of our results across age (Table 4), income and education (Table 5) subgroups. Table 4 shows the results for three different age groups, under 50, 50-65 and 66+. In absolute terms, larger effects are estimated in population subgroups more at risk of AMI, namely men in the age group 50-65 and both man and women 66+. More specifically, for men aged 50-65 and $66+$ we observe a reduction in the incidence of about 5 cases every 100'000 inhabitants per month. Notice that for women, the effect in the age group more at risk of AMI-women aged $66+$ - is now large and significant.

In relative terms, the story is quite different since for men the effect is larger for the subgroup under 50 (20\% reduction with respect to the mean incidence) and 50-65 (17\%). The difference between absolute and relative terms is due to the difference in the risk of AMI across subgroups but also to the different likelihood of each subgroup to attend bars and restaurants. We argue that younger people (under 66) are more likely to go to bars and restaurants and so more exposed to ETS before of the policy implementation.

The next step is to investigate whether the public smoking ban had an heterogeneous effect across income and education groups. We argue that this analysis is particularly relevant from a policy perspective since it concerns the potential impact of the policy on health inequality. Indeed, a differential impact of the policy across socio-economic group would exacerbate (in the case of a larger reduction among richer and high educated) or reduce the level of health inequality in the incidence of AMI. Ideally, one should use individual data for this kind of analysis, but the hospital register provides us only geographical information on patients' residence. For this reason, we implement the analysis at the smallest possible level of aggregation, the region. As explained in Section 4, this level of aggregation allows us to exploit the within canton variation in the level of income and education, and then control for institutional confounders at cantonal level. In particular, using data on the average median income between 2004 and 2010, we split the regions in two groups high vs. low income. We do the same for education using 2000 census data on education attainment. Table 5 clearly shows evidence of heterogeneity across both dimensions, but in particular across income groups. It indicates that the effect of the ban affected mainly low income and low education regions. In these regions, the estimated reduction in AMI incidence is almost twice the average effect estimated in Table 3, while the reduction in the richest and more educated regions is in most

\footnotetext{
${ }^{6}$ The results, available upon request, are larger than those reported in Table 3, and very close to the regional estimates.
} 
cases small and not statistically significant.

Finally, we test whether the effect of the public smoking ban has been larger in cantons that implemented the more severe regulation, as described in Section 2. We test this by including in the regression two dummies that capture the effect of the two different regulations, mild and severe. Table 6 shows the results by age. The table clearly indicates that the public smoking ban had a significant impact on AMI only in regions where a more severe regulation was implemented. As previously discussed, mild regulation has been implemented mainly in smaller cantons, also charachterized by the absence of metropolitan areas. On the other hand, we might also expect that the public smoking ban had larger effects in metropolitan areas charachterized by a large number of bars and restaurants. Therefore, we avoid speculating on the results reported in Table 6, saying that mild regulation are not effective in reducing the incidence of AMI hospitalizations.

\subsection{Robustness checks}

In this section we implement a set of robustness checks as described in Section 4.1. The first set of robustness checks are aimed to test the identification strategy of this paper. First we implement what we call an "unconfoundedness test", in which we test whether the policy affected a set of health outcomes, namely the incidence of lung, prostate and breast cancer, that should not be affected by the policy at least in the short run. The lung cancer affects both men and women, while the other prostate and breast cancer are sex specific. Even though the lung cancer is affected by ETS, we should not be able to observe effects in the short term. This test is meant to verify whether we are confounding the effect of the policy with some other unobservable trend or confounder factor. The test reported in Table 7 shows no effect of the public smoking ban on the incidence of all these health outcomes.

Second, we implement a sort of placebo tests to verify that there are no other jumps in the AMI distribution before or after the real implementation of the policy. As argued by Carpenter et al. (2011) this test is particularly suitable to test the endogeneity of the public policy because it allows to control for one-year lead of the smoking ban. Table 8 shows the results of this test. The table clearly shows that there is no evidence of any significant discontinuity in the distribution of the AMI hospitalizations before or after the real implementation.

Another robustness check that indirectly tests our identification strategy is to verify weather the reduction in AMI hospitalizations is larger during the winter season, when people stay more often inside the public place because of the adverse weather conditions. We show the results in Table A.1, where we report the average effect at the baseline (from April to October), and the interaction with the winter season (from November to March). As expected, the reduction in 
AMIs during the winter period is almost twice the reduction we observe during the rest of the year (compare the size of the two coefficients). Again, the results support our identification strategy.

The last robustness check concerns the estimations of the standard errors. As already discussed, to take into account the two potential sources of correlation, within (over time) and between regions, we use a two-way clustering strategy. As robustness check we use an OLS fixed effects estimator with panel-corrected standard errors (PCSE). It estimates the variance-covariance matrix assuming that the disturbances are by default heteroskedastic and contemporaneously correlated across panels, and it allows errors to be autocorrelated (first order auto-correlation specific to each panel). Since this model estimates the full variance-covariance matrix and so a very large number of time parameters (107), we avoid to include a full set of time fixed effects. We substitute them with year and month fixed effects (18 parameters).

Table A.2 shows that results from PCSE are very similar to those reported in the main text.

\section{Conclusion}

In this paper we assess the causal effect of the introduction of public smoking bans in Switzerland on AMI hospitalizations. We show that this anti-smoking policy implemented in Switzerland were effective in reducing the cases of AMI. Our results are robust to different model specifications and the large battery of tests implemented in this paper never casts doubt on our identification strategy.

On average, the introduction of public smoking bans leads to a reduction of about $10-12 \%$ of AMI hospitalization. However, we found large heterogeneity in the effect of interest across sex and age groups. In absolute terms, we found evidence of larger reductions in AMI hospitalizations among men 50+, the subgroup of the population with the largest incidence of AMI. Among women, we found evidence of a significant reduction in AMI hospitalizations only in the age group 66+, being them the only women subgroup really at risk of AMI. In relative terms, the largest reduction (roughly -20\%) was observed among men under 66, the subgroup of the population-among those at risk of AMI - that more often should go to bars and restaurant.

We also exploit the spatial heterogeneity in the effect of public smoking bans by focusing our analysis on very small regions (spatial mobility regions), which allows us to hold constant the confounding effect of institutional factors at cantonal level. Such analysis shows that the policy was more effective in poorer and less educated regions and in regions that implement a more severe regulation.

Our analysis is of particular relevance from a policy perspective for at least two important reasons. First, from a public health perspective, our paper shows that improving the quality of air in public places through smoking bans has a positive impact on population health. Additionally, 
our results demonstrate that the impact of the public smoking ban is even more effective in the areas with low income and low education. In these areas the AMIs' reduction is almost twice as large as the average effect. Assuming a positive correlation between health, income and education, the health improvement should be larger in areas with a poorer level of health. This suggests that such a public health intervention might be also able to reduce inequalities in health.

Secondly, this policy leads to a significant reduction of health related costs. In the USA, the American Hearth Association (2014) estimates for 2010 a total cost of 204.4 billions dollars due to hearth diseases. Even in Switzerland, the second country in the world for life expectancy at birth (OECD 2013), AMI is the leading cause of death and it represents a huge economic burden. For instance, Wieser et al. (2012) estimate that in 2008 the total direct costs of acute coronary syndrome (of which AMIs represent more than $80 \%$ of the costs) were more than 1 billion Swiss Francs. To this large cost we should add 500 millions of indirect costs due to production losses. Therefore a reduction of 10-12\% of AMI hospitalizations means saving at least 150 millions per year.

Finally, we address one final consideration. Even though we are able to evaluate the reduction in AMI hospitalizations due to this important public policy, we are not able to assess to what extent this reduction was due to a reduction of ETS exposure among smokers and non-smokers (through a reduction in second hand smoke exposure). Considering the previously cited studies on the effect of public smoking bans on smoking behavior, it is reasonably to believe that this reduction mainly comes from reduction in ETS exposure among non smokers. We will carry out further research to disentangle between these two effects by using individual survey data and administrative data on cigarette consumption. 


\section{References}

Adda, J. and Cornaglia, F. (2010) "The effect of bans and taxes on passive smoking", American Economic Journal: Applied Economics, 2: 1-32.

American Heart Association (2014) "Heart Disease and Stroke Statistics - 2014 Update". Circulation, 129: $28-292$.

Anger, S., Kvasnicka, M. and Siedler, T. (2011) "One last puff? Public smoking bans and smoking behavior", Journal of health economics, 30: 591-601.

Argacha, J. F., Adamopoulos, D., Gujic, M., Fontaine, D., Amyai, N., Berkenboom, G. and van de Borne, P. (2008) "Acute effects of passive smoking on peripheral vascular function", Hypertension, 51: 1506-11.

Barr, C. D., Diez, D. M., Wang, Y., Dominici, F. and Samet, J. M. (2012) "Comprehensive smoking bans and acute myocardial infarction among Medicare enrollees in 387 US counties: 1999-2008", American Journal of Epidemiology, 176: 642-8.

Beck, N. and Katz, J. N. (1995) "What to do (and not to do) with Time-Series Cross-Section Data", The American Political Science Review, 89: 634-47.

Bertrand, M., Duflo, E. and Mullainathan, S. (2004) "How Much Should We Trust Differences-in-Differences Estimates?", The Quarterly Journal of Economics, 119: 249-75.

Buonanno, P. and Ranzani, M. (2013) "Thank you for not smoking: Evidence from the Italian smoking ban", Health Policy, 109: 192-9.

Cameron C., Gelbach J., Miller D. (2011) "Robust Inference with Multi-way Clustering". Journal of Business and Economic Statistics, 29(2): 238-249.

Carpenter, C., Postolek, S. and Warman, C. (2011) "Public-Place Smoking Laws and Exposure to Environmental Tobacco Smoke (ETS)", American Economic Journal: Economic Policy, 3: 35-61.

Cawley, J., Markowitz, S. and Tauras, J. (2004) "Lighting up and slimming down: the effects of body weight and cigarette prices on adolescent smoking initiation", Journal of health economics, 23: 293-311.

Cowley J. and Ruhm C. (2011) "The economics of Health Behaviours". In Pauly M.V., McGuire T.G., and Barros P.P. HandBook of Health Economics, 2: 95-199.

Celermajer, D. S., Adams, M. R., Clarkson, P., Robinson, J., McCredie, R., Donald, A. and Deanfield, J. E. (1996) "Passive smoking and impaired endothelium-dependent arterial dilatation in healthy young adults", New England Journal of Medicine, 334: 150-5.

Cutler, D. M. and Lleras-Muney, A. (2010) "Understanding differences in health behaviors by education", Journal of health economics, 29: 1-28.

Di Valentino, M., Muzzarelli, S., Rigoli, A., Limoni, C., Pedrazzini, G., Barazzoni, F. and Gallino, A. F. (2011) "Reduced hospitalization for st-elevation myocardial infarction after introduction of smoking ban in public places in canton Ticino, southern Switzerland", Journal of the American College of Cardiology, 57 (14).

Evans, W. N., Farrelly, M. C. and Montgomery, E. (1999) "Do Workplace Smoking Bans Reduce Smoking?", American Economic Review, 89: 728-47.

Glantz, S. A. and Parmley, W. W. (1991) "Passive smoking and heart disease. Epidemiology, physiology, and biochemistry", Circulation, 83: 1-12. 
Insam, C., Paccaud, F. and Marques-Vidal, P. (2013) "Trends in hospital discharges, management and in-hospital mortality from acute myocardial infarction in Switzerland between 1998 and 2008", BMC public health, 13: 270.

Jones, A. M., Laporte, A., Rice, N. and Zucchelli, E. (2013) "Do public smoking bans have an impact on active smoking? Evidence from the UK", Health Economics.

Law, M. R., Morris, J. K. and Wald, N. J. (1997) "Environmental tobacco smoke exposure and ischaemic heart disease: an evaluation of the evidence", BMJ (Clinical research ed.), 315: 973-80.

Meyer, K., Simmet, A. and Junker, C. (2007) "Acute myocardial infarction and associated deaths in Switzerland an approach to estimating incidence", Kardiovaskulre Medizin, 10: 279-84.

Meyers, D. G., Neuberger, J. S. and He, J. (2009) "Cardiovascular effect of bans on smoking in public places", Journal of the American College of Cardiology, 54: 1249-55.

OECD (2013), Health at a Glance 2013: OECD Indicators, OECD Publishing. http://dx.doi.org/10.1787/health_glance-2013-en

Pieroni, L., Chiavarini, M., Minelli, L. and Salmasi, L. (2013) "The role of anti-smoking legislation on cigarette and alcohol consumption habits in Italy", Health policy, 111: 116-26.

Richiardi, L., Vizzini, L., Merletti, F. and Barone-Adesi, F. (2009) "Cardiovascular benefits of smoking regulations: The effect of decreased exposure to passive smoking", Preventive medicine, 48: 167-72.

Ruhm, C. J. (2007) "A Healthy Economy Can Break Your Heart", Demography, 44: 829-48.

Ruhm, C. J. (2005) "Healthy living in hard times", Journal of health economics, 24: 341-63.

Sargent, R. P., Shepard, R. M. and Glantz, S. A. (2004) "Reduced incidence of admissions for myocardial infarction associated with public smoking ban: before and after study", BMJ (Clinical research ed.), 328: $977-80$.

Shetty, K. D., DeLeire, T., White, C. and Bhattacharya, J. (2011) "Changes in U.S. hospitalization and mortality rates following smoking bans", Journal of Policy Analysis and Management, 30: 6-28.

Teo, K. K., Ounpuu, S., Hawken, S., Pandey, M., Valentin, V., Hunt, D., Diaz, R., Rashed, W., Freeman, R. and Jiang, L. (2006) "Tobacco use and risk of myocardial infarction in 52 countries in the INTERHEART study: a case-control study", The Lancet, 368: 647-58.

Wieser S., Rüthemann I., De Boni S., et al. (2012) "Cost of acute coronary syndrome in Swizterland". Swiss Med Wkly; 142:w13655.

Windham, G. C., Hopkins, B., Fenster, L. and Swan, S. H. (2000) "Prenatal active or passive tobacco smoke exposure and the risk of preterm delivery or low birth weight", Epidemiology, 11: 427-33. 
Table 1: Implementation of smoking bans (SB) in the Swiss cantons

\begin{tabular}{lcc}
\hline \hline Canton & SB implemented in & More severe regulation \\
\hline AG & 05.2010 & \\
AI & 05.2010 & $\mathrm{X}$ \\
AR & 01.2011 & $\mathrm{X}$ \\
$\mathrm{BE}$ & 07.2009 & $\mathrm{X}$ \\
$\mathrm{BL}$ & 05.2010 & $\mathrm{X}$ \\
$\mathrm{BS}$ & 04.2010 & $\mathrm{X}$ \\
$\mathrm{FR}$ & 01.2010 & $\mathrm{X}$ \\
$\mathrm{GE}$ & 11.2009 & \\
$\mathrm{GL}$ & 05.2010 & $\mathrm{X}$ \\
$\mathrm{GR}$ & 03.2008 & \\
$\mathrm{JU}$ & 05.2010 & \\
LU & 05.2010 & $\mathrm{X}$ \\
$\mathrm{NE}$ & 04.2009 & \\
NW & 05.2010 & $\mathrm{X}$ \\
OW & 05.2010 & \\
SG & 07.2010 & $\mathrm{X}$ \\
SH & 05.2010 & \\
SO & 01.2009 & $\mathrm{X}$ \\
SZ & 05.2010 & $\mathrm{X}$ \\
TG & 05.2010 & $\mathrm{X}$ \\
TI & 04.2007 & \\
UR & 09.2009 & \\
VD & 09.2009 & \\
VS & 07.2009 & \\
ZG & 03.2010 & \\
ZH & 05.2010 & \\
\hline \hline
\end{tabular}


Table 2: Average number of AMI hospitalizations per month at cantonal and regional level and incidence per 100'000 inhabitants, by age and sex

\begin{tabular}{|c|c|c|c|c|c|c|}
\hline & \multicolumn{3}{|c|}{ CANTONAL VALUES } & \multicolumn{3}{|c|}{ REGIONAL VALUES } \\
\hline & \# AMIs & (S.D.) & Incidence & \# AMIs & (S.D.) & Incidence \\
\hline \multicolumn{7}{|l|}{ All } \\
\hline Total & 29.556 & $(31.328)$ & 10.094 & 7.250 & $(7.545)$ & 11.001 \\
\hline Under 50 & 3.580 & $(4.266)$ & 1.798 & 0.878 & $(1.317)$ & 1.905 \\
\hline $50-65$ & 8.654 & $(9.752)$ & 15.721 & 2.123 & $(2.525)$ & 18.968 \\
\hline $66+$ & 17.321 & $(18.557)$ & 37.630 & 4.249 & $(4.759)$ & 44.417 \\
\hline \multicolumn{7}{|l|}{ Men } \\
\hline Total & 20.227 & $(21.598)$ & 14.124 & 4.961 & $(5.243)$ & 15.402 \\
\hline Under50 & 3.069 & $(3.733)$ & 3.022 & 0.753 & $(1.186)$ & 3.198 \\
\hline $50-65$ & 7.032 & $(8.006)$ & 25.481 & 1.725 & $(2.124)$ & 30.823 \\
\hline $66+$ & 10.126 & $(11.007)$ & 55.150 & 2.484 & $(2.908)$ & 64.378 \\
\hline \multicolumn{7}{|l|}{ Women } \\
\hline Total & 9.329 & $(10.291)$ & 6.182 & 2.288 & $(2.826)$ & 6.703 \\
\hline Under 50 & 0.511 & $(0.941)$ & 0.530 & 0.125 & $(0.395)$ & 0.565 \\
\hline $50-65$ & 1.623 & $(2.204)$ & 5.941 & 0.398 & $(0.782)$ & 7.001 \\
\hline $66+$ & 7.195 & $(8.061)$ & 25.604 & 1.765 & $(2.313)$ & 30.399 \\
\hline$N$ & 2808 & & & 11448 & & \\
\hline
\end{tabular}


Table 3: Effect of public smoking ban on AMI incidence, by sex

\begin{tabular}{|c|c|c|c|}
\hline & $\mathrm{A}$ & $\mathrm{B}$ & $\mathrm{C}$ \\
\hline \multicolumn{4}{|c|}{ Panel A: cantonal estimates } \\
\hline Total & $\begin{array}{l}-0.869^{* * *} \\
(0.317)\end{array}$ & $\begin{array}{l}-0.854^{* * *} \\
(0.328)\end{array}$ & $\begin{array}{l}-0.795^{* *} \\
(0.346)\end{array}$ \\
\hline Men & $\begin{array}{l}-1.489^{* * *} \\
(0.423)\end{array}$ & $\begin{array}{l}-1.495^{* * *} \\
(0.430)\end{array}$ & $\begin{array}{l}-1.364^{* * *} \\
(0.495)\end{array}$ \\
\hline Women & $\begin{array}{r}-0.279 \\
(0.426)\end{array}$ & $\begin{array}{r}-0.252 \\
(0.439)\end{array}$ & $\begin{array}{r}-0.263 \\
(0.443)\end{array}$ \\
\hline Obs. & 2808 & 2808 & 2808 \\
\hline$N$ & 26 & 26 & 26 \\
\hline \multicolumn{4}{|c|}{ Panel B: regional estimates } \\
\hline Total & $\begin{array}{l}-1.265^{* * *} \\
(0.383)\end{array}$ & $\begin{array}{l}-1.257 \text { *** } \\
(0.373)\end{array}$ & $\begin{array}{l}-1.105^{* * *} \\
(0.391)\end{array}$ \\
\hline Men & $\begin{array}{l}-2.134 \text { *** } \\
(0.688)\end{array}$ & $\begin{array}{l}-2.144 \text { *** } \\
(0.686)\end{array}$ & $\begin{array}{l}-1.964 \text { *** } \\
(0.741)\end{array}$ \\
\hline Women & $\begin{array}{c}-0.418^{*} \\
(0.243)\end{array}$ & $\begin{array}{l}-0.425 * \\
(0.245)\end{array}$ & $\begin{array}{r}-0.305 \\
(0.275)\end{array}$ \\
\hline Obs. & 11448 & 11448 & 11448 \\
\hline$N$ & 106 & 106 & 106 \\
\hline Area \& time f.e. & $\mathrm{X}$ & $\mathrm{X}$ & $\mathrm{X}$ \\
\hline Monthly unemployment & & $\mathrm{X}$ & $\mathrm{X}$ \\
\hline Area specific trends & & & $\mathrm{X}$ \\
\hline
\end{tabular}

Notes: The table shows the coefficient on the effect of the public smoking ban on the incidence of AMI hospitalizations by sex. Standard errors are robust and clustered at canton and month level (two-way clustering).

Significance levels: ${ }^{* *} p<0.01,{ }^{* *} p<0.05,{ }^{*} p<0.1$. 
Table 4: Effect of public smoking ban on AMI incidence, by age and sex

\begin{tabular}{|c|c|c|c|}
\hline & under 50 & $50-65$ & $66+$ \\
\hline \multicolumn{4}{|c|}{ Regional estimates } \\
\hline Total & $\begin{array}{l}-0.365^{* * *} \\
(0.125)\end{array}$ & $\begin{array}{l}{ }^{-2.268^{* *}} \\
(1.151)\end{array}$ & $\begin{array}{l}{ }^{-4.328^{* * *}} \\
(1.666)\end{array}$ \\
\hline Men & $\begin{array}{l}-0.647^{* * *} \\
(0.246)\end{array}$ & $\begin{array}{l}-5.215^{* * *} \\
(1.739)\end{array}$ & $\begin{array}{l}-5.729 \text { ** } \\
(2.670)\end{array}$ \\
\hline Women & $\begin{array}{r}-0.092 \\
(0.080)\end{array}$ & $\begin{array}{r}0.637 \\
(1.031)\end{array}$ & $\begin{array}{l}-3.362^{* *} \\
(1.656)\end{array}$ \\
\hline Obs. & 11448 & 11448 & 11448 \\
\hline$N$ & 106 & 106 & 106 \\
\hline
\end{tabular}

Notes: The table shows the coefficient on the effect of the public smoking ban on the incidence of AMI hospitalizations by age and sex using model B as in Table 3. Standard errors are robust and clustered at canton and month level (two-way clustering). Significance levels: ${ }^{* * *} p<0.01,{ }^{* *} p<0.05,{ }^{*} p<0.1$. 
Table 5: Heterogeneity by income and education

\begin{tabular}{lcclc}
\hline \hline & Low Income & High Income & Low Educ & High Educ \\
\hline \multicolumn{2}{l}{ Regional estimates } & & & \\
\hline Total & $-1.947^{* * *}$ & -0.388 & $-1.541^{* * *}$ & $-0.974^{* *}$ \\
& $(0.523)$ & $(0.552)$ & $(0.454)$ & $(0.376)$ \\
Men & $-3.112^{* * *}$ & -1.079 & $-2.991^{* * *}$ & $-0.905^{* *}$ \\
& $(0.983)$ & $(0.951)$ & $(0.971)$ & $(0.323)$ \\
\multirow{2}{*}{ Women } & $-0.830^{* * *}$ & 0.267 & -0.142 & -1.074 \\
& $(0.267)$ & $(0.329)$ & $(0.534)$ & $(0.646)$ \\
\multirow{2}{*}{ Obs. } & 5724 & 5724 & 5724 & 5724 \\
$N$ & 53 & 53 & 53 & 53 \\
\hline \hline
\end{tabular}

Notes: The table shows the coefficient on the effect of public smoking ban on the incidence of AMI hospitalizations by education and income groups using model B as in Table 3. Standard errors are robust and clustered at canton and month level (two-way clustering).

Significance levels: ${ }^{* * *} p<0.01,{ }^{* *} p<0.05,{ }^{*} p<0.1$.

Table 6: Strictness of the law: mild vs. severe law

\begin{tabular}{|c|c|c|c|}
\hline & Total & Men & Women \\
\hline \multicolumn{4}{|c|}{ Regional estimates } \\
\hline Mild & $\begin{array}{r}-0.248 \\
(0.582)\end{array}$ & $\begin{array}{r}-0.505 \\
(0.974)\end{array}$ & $\begin{array}{r}-0.096 \\
(0.545)\end{array}$ \\
\hline Severe & $\begin{array}{l}-1.415^{* * *} \\
(0.366)\end{array}$ & $\begin{array}{l}-2.408^{* * *} \\
(0.629)\end{array}$ & $\begin{array}{l}-0.478^{* *} \\
(0.226)\end{array}$ \\
\hline Obs. & 11448 & 11448 & 11448 \\
\hline$N$ & 106 & 106 & 106 \\
\hline
\end{tabular}

Notes: The table shows the coefficient on the effect of the public smoking ban on the incidence of AMI hospitalizations using two dummies for the ban (severe and mild implementation) using model B as in Table 3. Standard errors are robust and clustered at canton and month level (two-way clustering).

Significance levels: ${ }^{* * *} p<0.01,{ }^{* *} p<0.05,{ }^{*} p<0.1$. 
Table 7: Unconfoundness test: effect of the ban on the incidence of lung, prostate and breast cancer

\begin{tabular}{|c|c|c|c|}
\hline & Lung cancer & prostate cancer & breast cancer \\
\hline \multicolumn{4}{|c|}{ MS region estimates } \\
\hline Smoking Ban & $\begin{array}{r}-0.002 \\
(.005)\end{array}$ & $\begin{array}{c}-0.001 \\
(.020)\end{array}$ & $\begin{array}{c}-.028 \\
(.052)\end{array}$ \\
\hline Obs. & 11448 & 11448 & 11448 \\
\hline$N$ & 106 & 106 & 106 \\
\hline
\end{tabular}

Notes: The table shows the coefficient on the effect of the smoking ban using model B as in Table 3. Standard errors are robust and clustered at canton and monthly level (two-way clustering).

Significance levels: ${ }^{* * *} p<0.01,{ }^{* *} p<0.05,{ }^{*} p<0.1$.

Table 8: Placebo test

\begin{tabular}{lccc}
\hline \hline & Total & Men & Women \\
\hline \multicolumn{2}{l}{ Regional estimates } & & \\
\hline 1 year lag & -.127 & .051 & -.310 \\
& $(.531)$ & $(.945)$ & $(.381)$ \\
Smoking Ban & $-1.160^{* *}$ & $-2.034^{* *}$ & -.308 \\
& $(.484)$ & $(.899)$ & $(.315)$ \\
& & & \\
1 year lead & .601 & .740 & .447 \\
& $(.663)$ & $(.877)$ & $(.522)$ \\
Obs. & 11448 & 11448 & 11448 \\
$N$ & 106 & 106 & 106 \\
\hline \hline
\end{tabular}

Notes: The table shows the coefficient on the effect of the smoking ban using model B as in Table 3 and controlling for the effect of two placebo reforms one year before and after the real implementation. Standard errors are robust and clustered at canton and month level (two-way clustering).

Significance levels: ${ }^{* * *} p<0.01,{ }^{* *} p<0.05,{ }^{*} p<0.1$. 
Figure 1: Discontinuity in AMI hospital admissions after the smoking ban by sex
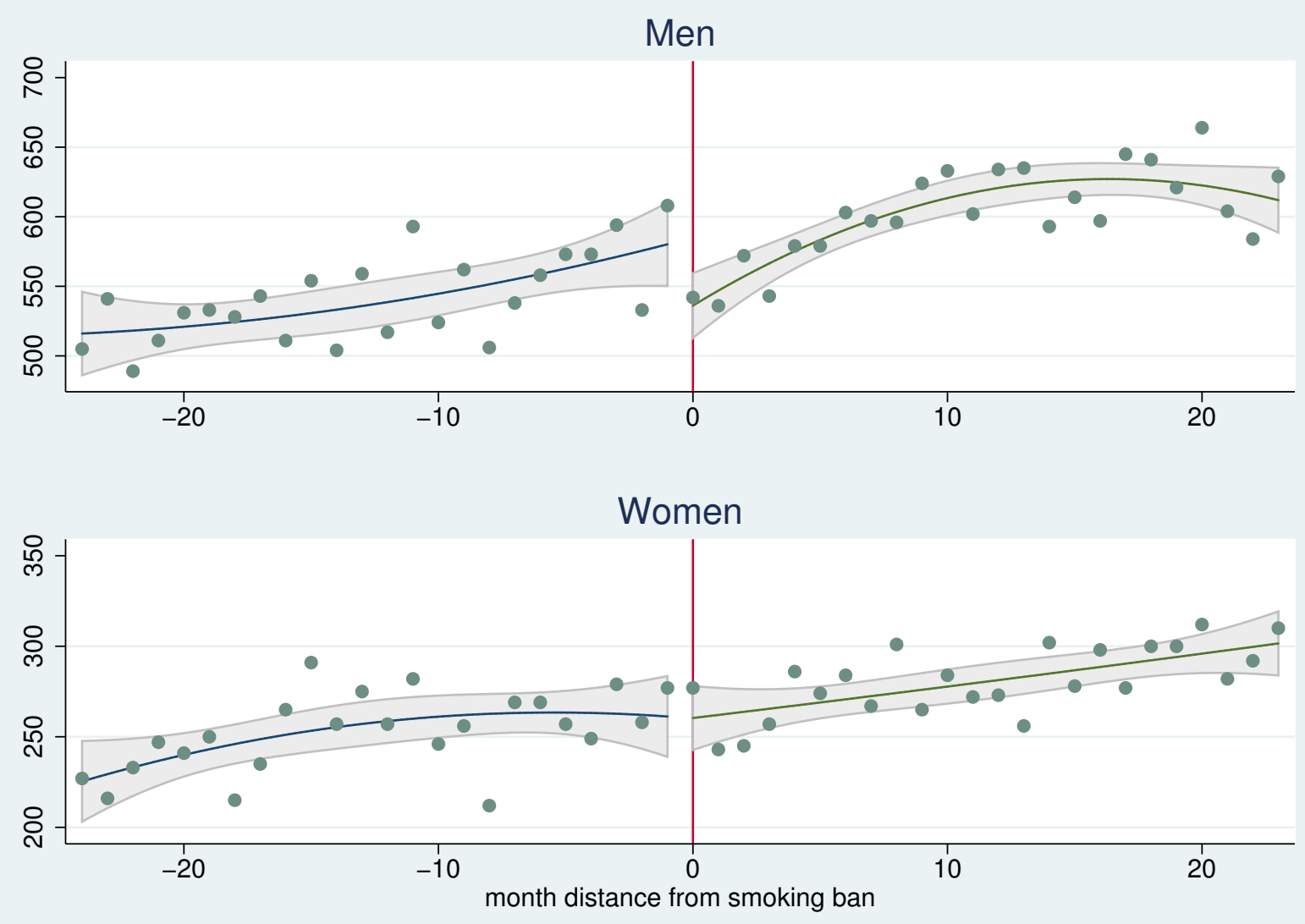
Figure 2: Discontinuity in AMI hospital admissions after the smoking ban by sex (residuals)

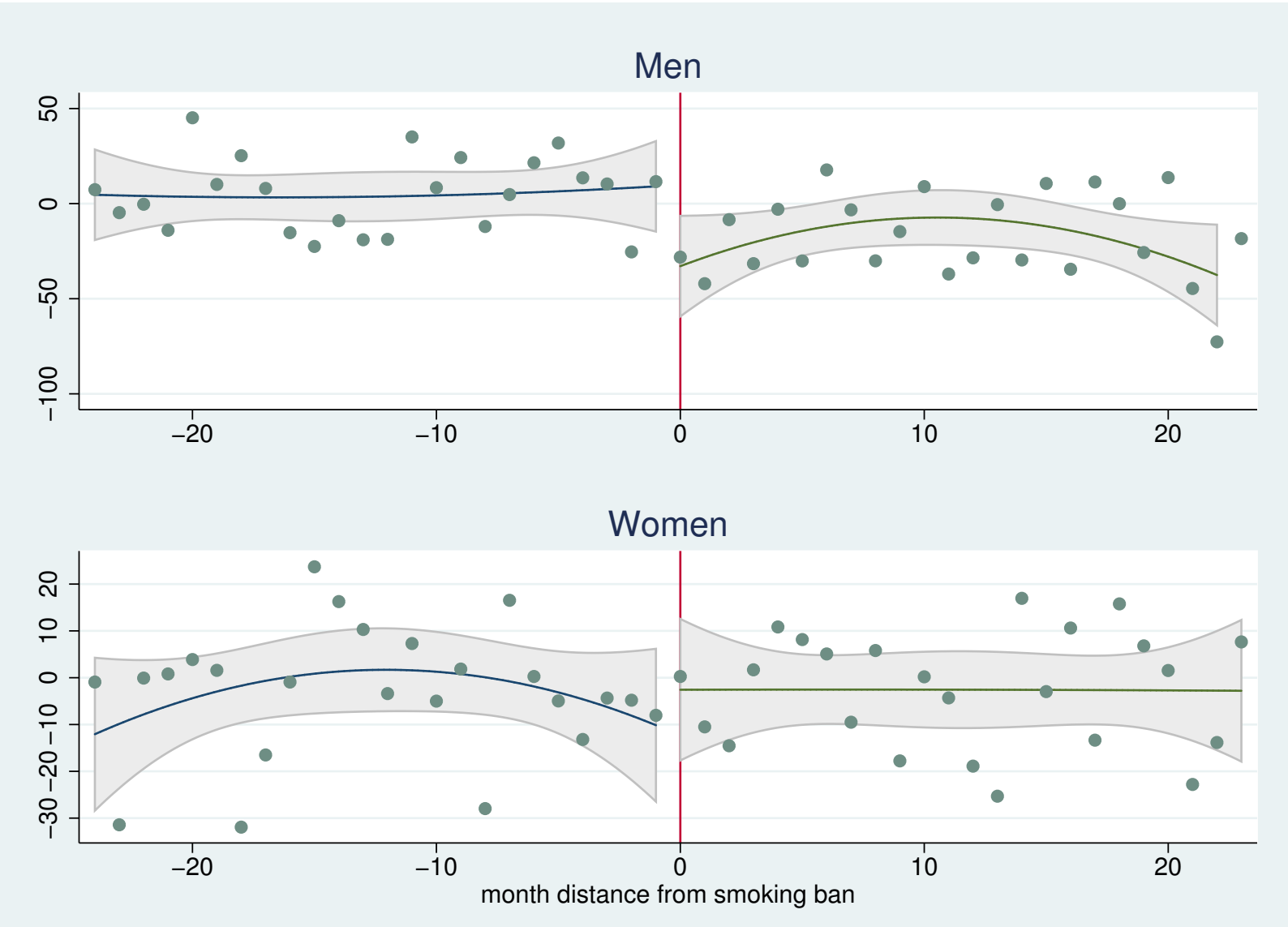




\section{A Appendix}

Table A.1: Seasonal heterogeneity

\begin{tabular}{lccc}
\hline \hline & Total & Men & Women \\
\hline Regional estimates & & & \\
\hline Smoking ban & $-.926^{* * *}$ & $-1.577^{* *}$ & -.353 \\
& $(.304)$ & $(.580)$ & $(.258)$ \\
Smoking ban*winter & -.782 & $-1.337^{* *}$ & -.169 \\
& $(.508)$ & $(.558)$ & $(.748)$ \\
& & & \\
Obs. & 11448 & 11448 & 11448 \\
$N$ & 106 & 106 & 106 \\
\hline \hline
\end{tabular}

Notes: The table shows the coefficient on the effect of the smoking ban using model B as in Table 3 plus an interaction term for the winter season (November to March). Standard errors are robust and clustered at canton and month level (two-way clustering)

Significance levels: ${ }^{* *} p<0.01,{ }^{* *} p<0.05,{ }^{*} p<0.1$.

Table A.2: Panel corrected standard errors estimates

\begin{tabular}{|c|c|c|c|}
\hline & Total & Men & Women \\
\hline \multicolumn{4}{|c|}{ Regional estimates } \\
\hline Smoking ban & $\begin{array}{l}-1.155^{\text {*** }} \\
(.383)\end{array}$ & $\begin{array}{l}-1.721^{* *} \\
(.615)\end{array}$ & $\begin{array}{r}-.599 \\
(.368)\end{array}$ \\
\hline Obs. & 11448 & 11448 & 11448 \\
\hline$N$ & 106 & 106 & 106 \\
\hline
\end{tabular}

Notes: The table shows the coefficient on the effect of the smoking ban controlling for time and month fixed effects and monthly unemployment rate. The effect is estimated using panel corrected standard errors assuming first order autocorrelation, $\operatorname{AR}(1)$. Significance levels: ${ }^{* *} p<0.01,{ }^{* *} p<0.05,{ }^{*} p<0.1$. 


\section{IdEP Economic Papers}

The series IdEP Economic Papers, ideally continues the work of the "Quaderni della Facoltà" the publication of which began in 1998 and ended in 2013.

For a complete list of the Quaderni see: http://econpapers.repec.org/paper/lugwpaper/

IdEP Economic Papers also gathers the legacy of the CEPRA Working Papers, published from 2012 to 2013.

The full list at: http://econpapers.repec.org/paper/lugwcepra/

\section{4:}

No. 01

F. Mazzonna, F. Peracchi, Unhealthy retirement? Evidence of occupation heterogeneity

No. 02

L. Di Giorgio, M. Filippini, G. Masiero, The relationship between costs and quality in nonprofit nursing homes

No. 03

F.C. Billari, V. Galasso, Fertility decisions and pension reforms : evidence from natural experiments in Italy

No. 04

M. Jametti, M. Joanis, Elections and de facto expenditure decentralization in Canada

No. 05

M. Jametti, Weathering the global financial crisis : is direct democracy of any help?

No. 06

U. Pagano, M. Vatiero, Costly institutions as substitutes: novelty and limits of the Coasian approach

No. 07

R. Parchet, Are local tax rates strategic complements or strategic substitutes?

No. 08

R. Ippoliti, M. Vatiero, An analysis of how 2002 judicial reorganization has impacted on the performance of the First Instance Courts (Preture) in Ticino

No. 09

F. Mazzonna, P. Salari, Short term effects of public smoking bans on health 